НАУКИ О ЗЕМЛЕ

"НАУКА. ИННОВАЦИИ. ТЕХНОЛОГИИ", № 3, 2019

25.00 .17

УДК 622.279 .72

В.В. Качалов,

B.Н. Сокотущенко

Е.В. Земляная,

А.В. Волохова
РАЗРАБОТКА И ЭКСПЛУАТАЦИЯ НЕФТЯНЫХ

И ГАЗОВЫХ МЕСТОРОЖДЕНИЙ

Объединенный институт высоких температур РАН, Москва, Россия

E-mail: sokotushenko@mail.ru

объединенный институт ядерных исследований,

г. Дубна, Россия

\title{
ОБЗОР МЕТОДОВ \\ ПОВЫШЕНИЯ КОМПОНЕНТООТДАЧИ ПРИ РАЗРАБОТКАХ ГАЗОКОНДЕНСАТНЫХ МЕСТОРОЖДЕНИЙ
}

В данном обзоре исследований отечественных и зарубежных авторов рассматривается проблема повышения компонентоотдачи газоконденсатных пластов.

Введение. Обсуждаются причины снижения компонентоотдачи на газоконденсатных месторождениях и варианты решения этой проблемы. Повышение производительности действующей скважины основан на явлении понижения давления начала конденсации газоконденсата при увеличении в его составе углеводородов (пентан + высшие). Рассматриваются также методы закачки воды или инертного газа по контуру месторождения с целью поддержания пластового давления на закритическом уровне, однако распространения они не получили.

Материалы и методы. В основе методов рациональной эксплуатации лежит идея о необходимости поддержания пластового давления выше давления конденсации. В отличие от нефтедобычи, при эксплуатации газоконденсатных месторождений используются, как правило, режимы разработки продуктивного пласта «на истощение). В промышленных масштабах для поддержания пластового давления на закритическом уровне применяется единственный метод сайклинг-процесс, т.е. закачка в пласт сухого метана [1].

Результаты Применение той или иной схемы разработки месторождения с воздействием на пласт должно позволить дополнительно извлечь некоторую часть остаточных запасов газа и конденсата. На нефтяных месторождениях широко применяется промывка скважин различными растворами. Для газоконденсатных месторождений, кроме растворителей, устраняющих кольматацию прискважинной зоны, предлагается закачка реагентов, выделяющих тепло в процессе реакции. За счет повышения температуры фазовое равновесие газоконденсатной смеси смещается в сторону газовой фазы, что должно приводить кувеличению выхода газоконденсата. В статье рассматриваются некоторые результаты работ, посвященных решению вопросов максимально полного извлечения газа из продуктивных пластов.

Выводы. и обсуждения.

Все перспективные физико-химические методы воздействия на пласт с целью повышения конденсатоотдачи можно классифицировать следующим образом: 1. Рациональная эксплуатация отдельной скважины или месторождения в целом. 2. Закачка газа или жидкости в продуктивный пласт. 3. Использование растворителей. 4. Воздействие взрывом, акустическими и упругими волнами, электромагнитное воздействие. 5. Тепловое воздействие.

Исследование показало, что различные сценарии эксплуатации могут скорректировать состав извлекаемой продукции и количество выпадающего конденсата в пласте.

Ключевые слова: газоконденсатные месторождения, углеводородное сырьё, продуктивный пласт, методы повышения компонентоотдачи, ретроградный конденсат. 


\author{
V. V. Kachalov, Joint Institute of High Temperatures of the Russian Academy of Sciences, \\ Moscow, Russia \\ V.N. Sokotushchenko E-mail: sokotushenko@mail.ru \\ E.V. Zemlyanaya, Joint Institute for Nuclear Research, \\ A. V. Volokhova Dubna, Russia
}

\title{
OVERVIEW OF THE COMPONENT ENHANCEMENT METHODS IN DEVELOPMENT OF THE GAS CONDENSATE FIELDS
}

In this review of researches of domestic and foreign authors the problem of increase of a component of gas condensate layers is considered.

Introduction. The reasons for the reduction of component recovery in gas condensate fields and solutions to this problem are discussed. Improving the performance of existing wells based on the phenomenon of decompression beginning of condensation of the condensate with increasing of the composition of hydrocarbons «pentane + higher». Methods for pumping water or inert gas along the field circuit to maintain reservoir pressure at the supercritical level are also considered, but they have not been distributed.
Materials and methods. The rational operation methods are based on the idea of maintaining resenvoir pressure above the condensation pressure. In contrast to oil produc- tion, in the operation of gas condensate fields are used, as a rule, modes of development of productive formation «at depletion». On an industrial scale, the only method used to maintain resenvoir pressure at the supercritical level is the Cycling process, i.e. injection of dry methane into the reservoir [1].

Results and discussions. The use of a particular field development scheme with an impact on the resenoir should allow for the additional extraction of some of the residual gas and condensate reserves. In oil fields, well washing with various solutions is widely used. For gas-condensate fields, except for solvents, which eliminates mudding of nearfield is proposed the injection of reagents that produce heat during the reaction. Due to the increase in temperature, the phase equilibrium of the gas condensate mixture is shifted towards the gas phase, which should lead to an increase in the yield of gas condensate. The article discusses some of the results of the work devoted to solving the issues of the most complete extraction of gas from productive formations.

Summary. All promising physico-chemical methods of influence on the formation in order to increase condensate recovery can be classified as follows:

1. Rational operation of a single well or field as a whole.

2. Injection of gas or liquid into the reservoir.

3. Use of solvents.

4. Impact explosion, acoustic and elastic waves, electromagnetic impact.

5. Thermal effect.

The study showed that different operating scenarios can adjust the composition of the extracted products and the amount of condensate in the reservoir.

Keywords: $\quad$ gas condensate fields, hydrocarbon feedstock, reservoir, methods for enhancing component recovery, retrograde condensate. 


\section{ВВЕДЕНИЕ}

Эффективность разработки газовых и газоконденсатных месторождений оценивается, прежде всего, по полноте извлечения углеводородного сырья из пласта [2]. Принятые в отечественной практике способы разработки месторождения на режиме естественного истощения не позволяют извлекать углеводороды с достаточной полнотой, среднее извлечение газа для газовых месторождений составляет 85-90\%, для газоконденсатных -75 $85 \%$, а извлечение конденсата не превышает $30 \%$.

Для повышения компонентоотдачи истощенных газоконденсатных месторождений может быть использовано нагнетание в них углеводородных растворителей. Эти методы основаны на вовлечении выпавшего в пласте ретроградного конденсата в процесс фильтрации.

Масштабы и темп освоения ресурсов природных углеводородных систем в значительной степени связаны с разработкой залежей газо- и нефтегазоконденсата. С увеличением глубины бурения и в результате освоения новых месторождений их доля в балансе газонефтяных флюидов возрастает [3]. В то же время коэффициент извлечения ресурсов из недр на действующих газоконденсатных скважинах намного меньше, чем на нефтяных. Лишь в наиболее благоприятных случаях он достигает $60 \%$, оставаясь в среднем на уровне $45-50 \%[4]$

Такое различие, помимо характерных для газоконденсатных месторождений сложных геологических условий, объясняется особенностями термодинамических свойств газоконденсата [5], связанными с его аномальным поведением в двухфазной области. Опыт разработки газоконденсатных месторождений показывает, что одной из причин снижения продуктивности эксплуатационных скважин является значительное насыщение пористой среды призабойной зоны ретроградным конденсатом [6]. Это приводит к тому, что в зоне скважины в пористом продуктивном пласте скапливается конденсат (т.н. конденсатная пробка), снижающий газопроницаемость пласта и препятствующий выходу газовой фазы. При этом наиболее ценные компоненты углеводородного сырья остаются в жидкой фазе.

При движении газоконденсатного флюида при падении давления происходит выпадение жидкой фазы. Это связано со специфическими свойствами ретроградной области, которая существует на фазовой диаграмме газоконденсатной смеси. В области ретроградной конденсации (ретроградного испарения) при изотермическом снижении давления (изобарическом снижении температуры) происходит увеличение количества образовавшейся жидкой фазы (газовой фазы) в системе до максимального значения. Дальнейшее снижение давления (температуры) приводит к уменьшению объёма жидкой (газовой) равновесной фазы, а при определенном давлении (определенной температуре) жидкая (газовая) фаза исчезает, и многокомпонентная система снова переходит в однофазное газообразное (жидкое) состояние. Многие при- 
родные многокомпонентные системы обладают одной ретроградной областью. У пластовых смесей газоконденсатных месторождений наблюдается в большинстве случаев только область ретроградной конденсации. Ретроградные эффекты проявляются у различных по составу углеводородных многокомпонентных систем при разных значениях давлений и температур. Следует отметить, что термобарические условия, приводящие к ретроградным явлениям в пластовых смесях газоконденсатных месторождений, часто соответствуют давлениям и температурам, наблюдаемым в практике их разработки. Это вызывает выпадение жидких компонентов в газонасыщенных пластах, изменение состава добываемой продукции, а также продуктивности скважин. При этом жидкая фаза имеет меньшую фазовую проницаемость по отношению к газовой, поэтому происходит торможение жидкой фазы, увеличивается давление. Но в силу специфики фазовой диаграммы с ретроградной областью при увеличении давления происходит образование газовой фазы, которая имеет большую фазовую проницаемость. Таким образом, происходит сначала накопление жидкой фазы, приводящее к увеличению давления, а потом из-за образования газовой фазы жидкостная пробка «проталкивается», движение восстанавливается, снова происходит падение давления, образование жидкой фазы, т.е. описанный процесс повторяется.

В качестве легких углеводородных растворителей для воздействия на газоконденсатные залежи могут использоваться: этан, этан-пропановая фракция, широкая фракция лёгких углеводородов. Все эти растворители состоят практически из одних промежуточных углеводородных компонентов. Свойства этих компонентов как растворителей веществ нефтяной и газоконденсатной природы подробно исследованы в работах $[7,8,9]$.

Выполненные экспериментальные исследования $[10,11]$ позволили раскрыть механизм вытеснения конденсата этаном в условиях, когда газоконденсатная смесь является двухфазной со значительным преобладанием газовой фазы и с неподвижным до введения этана жидким конденсатом. Было показано, что выпавший конденсат тем эффективнее вытесняется этаном, чем значительнее пластовое давление превышает критическое давление $(4,88$ МПа) этана.

Оценка эффективности различных методов выполнялась сравнением выбранных методов с базовым сценарием, представляющим традиционную схему разработки залежи газа - истощение. В качестве альтернативных сценариев управления разработкой рассматривались методы поддержания пластового давления путем закачки в пласт различных агентов: сухого газа («сайклинг»), азота, воды и смешанного воздействия газа, и воды (водогазовое воздействие). Помимо этого, подбиралось оптимальное соотношение нагнетательных и добывающих скважин, величина компенсации закачки и темп отбора газа. В работе [12] дана оценка технологической эффективности методов увеличения конденсатоотдачи из ачимовских отложений Уренгойс- 
кого нефтегазоконденсатного месторождения. Отличительные особенности ачимовских пластов - это низкая проницаемость (порядка 1 мД) и аномально высокое начальное пластовое давление ( $\approx 600$ атм). Для моделирования методов повышения конденсатоотдачи на одном из участков авторами был подобран элемент разработки, в котором средние параметры соответствовали параметрам полномасштабной модели. Полученные результаты свидетельствуют, что при реализации закачки азота в условиях ачимовских отложений Уренгойского НГКМ ожидается относительное увеличение конденсатоотдачи на 40-50\%. При этом, данный вариант является эффективнее традиционного «истошения» по интегральному показателю, что позволяет говорить о перспективах его оценки в ОКР для разработки других газоконденсатных залежей.

Для проведения расчетов сайклинг-процесса в многопластовой газоконденсатной залежи авторы [13] предложили модифицированную гидродинамическую модель Black oil. Под фазами в предложенной модели подразумевают: пластовый (жирный) газ; пластовая углеводородная жидкость (нестабильный ретроградный конденсат); закачиваемый сухой газ. К укрупненным компонентам газодинамической модели были отнесены: газ (компоненты до бутанов включительно) растворенный в жирной пластовой газовой и углеводородной жидкой фазах; группу $\mathrm{C}_{5+}$; ; закачиваемый для поддержания давления сухой газ. Разработанная модель, позволяет, оставаясь в рамках уравнений Маскета-Мереса, моделировать недонасыщенные по $\mathrm{C}_{5+}$ пластовые системы.

В работе [14] аналитически и экспериментально исследовался процесс вытеснения из пористой среды углеводородной жидкости смесью углеводородных газов и диоксид углерода. Результаты исследования выявили механизм возникновения двухфазной фильтрации, а таюже изменения, происходящие с фазами - изменения объемов, плотности, вязкости и поверхностного натяжения.

На основании результатов лабораторных опытов на насыпной модели было установлено [15], что вытеснение газоконденсата сухим газом из модели неоднородного пласта при циклическом изменении давления может существенно повысить извлечение углеводородов $\mathrm{C}_{5+}$.

\section{МАТЕРИАЛЫ И МЕТОДЫ}

Технология разработки газовых месторождений, согласно [16], показывает целесообразность эксплуатации обводнившихся и обводняющихся газовых скважин с целью поддержания уровня добычи газа из месторождения и увеличения газоотдачи пласта. В результате выполненных исследований показано, что закачка попутно добываемой воды в низкопроницаемые и/или слабодренированные зоны пласта способствует дальнейшему повышению конечного коэффициента газоотдачи резконеоднородного по коллекторским свойствам пласта. Вопросы повышения конденсатоотдачи при 
использовании водогазового воздействия на газоконденсатный пласт рассмотрены в работе [17]. В результате серии опытов на физической и математической модели показано существенное преимущество водогазового воздействия перед заводнением. Увеличение конечного коэффициента извлечения конденсата составило 10\%. Также авторами выявлено формирование перед фронтом воды зоны повышенного содержания углеводородной жидкости.

Процесс вытеснения ретроградного конденсата обогащенным газом заключается в закачке в пласты газа, содержащего метан, этан, пропан и бутан $\left(\mathrm{C}_{1}-\mathrm{C}_{4}\right)$, с последующим вытеснением смеси пластовых углеводородов и обогащенного газа сухим газом. Выполненные эксперименты [18] показали, что выпавший конденсат может быть извлечен из пласта путем прокачки обогащенного газа. Механизм вытеснения ретроградного конденсата обогащенным газом может быть представлен на основе результатов исследований, описанных в монографии [19]. Результаты уже выполненных к настоящему времени исследований [20] показывают, что воздействие обогащенным газом на истощенные газоконденсатные месторождения может оказаться достаточно эффективным методом повышения их компонентоотдачи.

За рубежом также имеется обширный накопленный опыт по повышению компонентоотдачи при разработках газоконденсатных месторождений. Так, на основе лабораторных результатов [21] и численного моделирования одной скважины было проведено полевое испытание газовой скважины, на которой наблюдалась постепенное снижение производительности, вызванное выпадением конденсата на месторождении. Установлено, что обработка метанолом газоконденсатной скважины на месторождении Хаттерс Понд в течение первых 4 месяцев в два раза увеличивает добычу газа и конденсата, а при дальнейшей разработке, увеличение добычи поддерживается на уровне $50 \%$ от добычи без закачки метанола. Однако, необходимо принять меры предосторожности для обеспечения совместимости закачиваемого метанола как с пластовым солевым раствором, так и с пластовыми породами, что может снизить производительность скважины в два и более раз.

Явление «конденсатной пробки» есть результат воздействия комплекса факторов, включая свойства флюидной фазы, характеристики пластового потока, давления в пласте и в стволе скважины. Например, производительность скважин на месторождении Арун в Северной Суматре, Индонезия, значительно снизилась примерно через 10 лет после начала добычи. Исследования скважин, включая испытания на переходные процессы давления, показали, что потери были вызваны накоплением конденсата вблизи ствола скважины. Арун является одним из нескольких огромных газоконденсатных коллекторов, которые вместе содержат значительный глобальный ресурс. К другим крупным газоконденсатным ресурсам относятся Штокмановское месторождение РФ в Баренцевом море, Карачаганакское месторождение в Казахстане, месторождение Северное в Катаре, месторождение Южный Парс в 
Иране и месторождение Купиагуа в Колумбии. Исследователи из Техасского университета в Остине провели лабораторные испытания с использованием 3М фторуглеродных поверхностно-активных веществ [22]. Результаты по образцам керна коллектора, заблокированным конденсатом, свидетельствуют о удвоении значений относительной проницаемости газа и конденсата после обработки. Основываясь на этих многообещающих лабораторных данных, Chevron успешно протестировал эту методику в заблокированной газоконденсатной скважине в 2006 году.

Газоконденсатные скважины часто испытывают значительное снижение производительности после того, как давление в забое скважины падает ниже точки росы из-за выпадения конденсата в призабойной зоне. Тем не менее, по-прежнему отсутствует полное понимание того, как изменения состава влияют на производительность скважины. В исследовании [23] рассмотрена проблема восстановления газоконденсатных пластов с акцентом на изменение состава. Полное композиционное моделирование проводилось для исследования изменений состава и насыщенности конденсатом. Были смоделированы различные стратегии для получения продуцирующих последовательностей с улучшенным восстановлением. Влияние методов, таких как гидроразрыв пласта и закачка газа, на состав и восстановление газоконденсатной залежи также были исследованы. Кроме того, параметры, регулирующие закачку газа в газоконденсатный пласт, были скорректированы с использованием алгоритма математической оптимизации для получения оптимального извлечения. Исследование показало, что состав значительно варьируется во время истощения. Различные стратегии производства могут повлиять на составы флюидов и количество выпадающего конденсата в пласте. Принимая во внимание новое понимание того, как изменяется состав, состав выпадающих жидкостей может «контролироваться» и доизвлечение из газоконденсатных пластов может быть улучшено. Решение задачи математической оптимизации в случае закачки метана продемонстрировало, что оптимальные результаты не всегда достигаются при максимальных скоростях закачки газа. Газоконденсатные коллекторы демонстрируют сложное поведение потока ниже давления точки росы, вызванное изменением состава и созданием, и ростом конденсатноой пробки вокруг скважины, что существенно снижает относительную проницаемость для газового потока. В результате добыча газа снижается, а в пласте остается жидкий конденсат [24].

В диссертационной работе [25] приводятся результаты экспериментальных исследований, доказывающие важную роль сорбционно-десорбционных процессов в фазовых превращениях в продуктивном коллекторе, в распределении углеводородных компонентов между неподвижной и извлекаемой частями системы. Высококипящие компоненты пластовой углеводородной смеси, сорбируясь на стенках поровых каналов, могут изменять состав фильтрующегося флюида. Уменьшение сечения фильтрационных каналов 
может сопровождаться снижением проницаемости пласта и, как следствие, углеводородоотдачи.

Явления, обуславливаемые молекулярным взаимодействием флюидов со стенками пор, играют важную роль в условиях газоконденсатного или нефтяного пласта, представляющего собой высокодисперсную пористую среду с развитой поверхностью. Создан экспериментальный комплекс, позволяющий проводить исследования фазового поведения углеводородных и неуглеводородных флюидов в пористых средах и в свободном объёме в диапазоне температур $110 \ldots 420 \mathrm{~K}$ и давлений до 60 МПа. Показано, что сорбционнодесорбционные процессы, изменяя состав флюида в поровом пространстве, существенно влияют на его фазовое поведение. Полученные экспериментально обобщённые изотермы адсорбции углеводородных смесей позволяют количественно оценивать распределение компонентов между неподвижной и извлекаемой (фильтрующейся) частями системы с учётом влияния связанной воды. Использование полученных результатов в проектах разработки залежей, приуроченных к плотным низкопроницаемым коллекторам с трудноизвлекаемыми запасами углеводородов, в том числе вводимых в разработку залежей в ачимовских и нижнемеловых отложениях Западной Сибири, позволит существенно повысить их нефте-, газо-, конденсатоотдачу. Экспериментально установлены зависимости количества сорбирующихся в пристеночном слое углеводородов от их молекулярной массы, величины удельной поверхности и водонасышенности; определены критические параметры ряда характерных углеводородных смесей. Кроме того, установлено, что определяющим фактором различия процессов выпадения и испарения конденсата в пористых средах является макроскопическое расслоение жидкой и паровой фаз, обусловленное размером поровых каналов.

В статье [26] исследуется влияние скорости и межфазного натяжения на относительную проницаемость газоконденсата в области забоя скважины при высоких давлениях. Полученные результаты применяются к потоку газоконденсата в области забоя скважины. Посредством использования устойчивых и неустойчивых методов изучалось влияние относительной проницаемости на газовую и жидкую фазы. Эксперименты показали, что увеличение скорости потока приводит к увеличению относительной проницаемости обеих фаз. Возрастающее при этом межфазное натяжение уменьшает относительную проницаемость газовой фазы по сравнению с жидкой. В соответствии с числом Рейнольдса поток вдоль всего участка был ламинарным. Следует отметить, что при несоблюдении закона Дарси относительная проницаемость уменьшается вместе со скоростью потока.

Влияние отклонения от закона Дарси и уменьшения пор (pore proximity) на добычу газоконденсата нетрадиционными методами рассмотрено в статье [27] Переносные свойства и механизмы, а также фазовые переходы в замкнутом объеме значительно отличаются от них в свободном пространстве (bulk 
behavior). Вследствие взаимодействия молекул со стенками сосуда, а также вследствие межмолекулярного взаимодействия фазовые переходы претерпевают изменения в наноскважинах. К тому же, в наноскважинах, когда средняя длина свободного пробега молекул составляет порядка радиуса скважины, наблюдаются отклонения от закона Дарси. Это явление приводит к увеличению эффективной пронищаемости движущегося флюида. В исследовании авторы сфокусировались на определении и анализе влияния на конденсатоотдачу фазовых переходов и изменении фильтрационных свойств вследствие уменьшения пор (pore proximity). Кроме того, авторы анализируют влияние отклонения от стационарного потока на производительность скважины с помощью второго уравнения Кликенберга. В статье также изучено влияние различных взаимодействий между порами на производительность. Результаты показывают, что при уменьшении размера пор флюид ведет себя как сухой газ с уменьшающейся двухфазной областью, вследствие чего наблюдается выход конденсата и увеличение проницаемости. С учетом введенных ограничений уровень добычи газа не изменился, тогда как расход жидкости значительно возрос. Эффект фазовых переходов дает положительный вклад в добычу полезных ископаемых, в то время как изменение размера пор и проницаемости оказывает негативное воздействие на разработку месторождений. Типы взаимодействия между порами разных размеров имеют ярко выраженный эффект и определяют, какие из этих факторов оказывают наибольшее воздействие на производительность. Исследования показали отсутствие отклонений от закона Дарси на начальном этапе разработки месторождений, поскольку на этом этапе давление достаточно высокое. Входящий в линейный закон фильтрации Дарси коэффициент проницаемости определяется при исследовании кернов или на основе гидродинамических исследований. Исследованиями показано, что для пористых сред коэффициент проницаемости зависит от размера зерен и их дисперсности, коэффициента пористости, формы зерен и степени их сцементированности.

В связи с тем, что линейный закон фильтрации Дарси всё-таки является приближенным законом, при увеличении скорости фильтрации жидкости и соответствующем увеличении скоростного напора сделанное ранее при выводе линейного закона фильтрации допущение может оказаться несправедливым, тогда и возникнут погрешности в расчетах.

В статье [28] исследуется влияние межфазного натяжения на относительную проницаемость. Добавление поверхностно-активного вещества в вытесняющую водную фазу изменяет натяжение на границе фаз, которое в свою очередь может оказать существенное воздействие на относительную проницаемость. В статье представлены результаты экспериментов по изучению изменения двухфазной относительной проницаемости в водонефтяных системах. Представлены новые методы измерения относительной проницаемости. В частности, был усовершенствован способ стационарного измерения 
относительной проницаемости; доказано существование некоторого критического диапазона межфазного натяжения, в наибольшей степени влияюшего на относительную проницаемость. Здесь важно отметить, что в стандартном диапазоне относительная проницаемость возрастает по мере уменьшения межфазного натяжения.

Экспериментальное изучение относительной проницаемости околокритического газоконденсата представлено в работе [29]. Обычно залежи газоконденсата содержат систему жидкость-газ во время разработки. Такие системы сложно моделировать экспериментально, поскольку они почти не смешиваются при высоких давлении и температуре (обычно: Ркр > 300 бар, Ткр $>100{ }^{\circ} \mathrm{C}$ ). Существует метод упрощения лабораторных измерений при помощи использования двухкомпонентной жидкости с наблюдаемой ретроградной конденсацией и выбора температуры для контроля растворимости. Была проведена серия измерений относительной проницаемости на углеродном стержне умеренной проницаемости, используя смесь метанол/н-гексан в условиях слабого смешивания в присутствии воды. Для обеспечения слабой смешиваемости с метанолом в воду был добавлен карбонат калия. Эксперименты используют квазиравновесный метод в условиях, похожих на реализующиеся в месторождении газоконденсата вблизи скважины. Были исследованы потоки газа и конденсата в разных соотношениях действующих сил (числа капиллярности и числа Этвеша). Изучена относительная проницаемость в зависимости от состава жидкости и расхода, а также насыщенности конденсата и водяного пара. Зависимость относительной проницаемости от насыщенности смачивающей фазы сдвигается влево при увеличении расхода смачивающей фазы и уменьшении поверхностного натяжения. Исследования по измерению и моделированию явлений инерционного потока и потока с высоким числом капиллярности в относительной проницаемости газоконденсата, показали, что продуктивность большинства газового конденсата значительно падает при образовании конденсатной пробки, когда давление у забоя скважины падает ниже точки росы.

Наиболее важным параметром для определения продуктивности скважины является эффективная проницаемость газа вблизи скважины, где могут быть очень высокие скорости. Понимание характеристик высокоскоростного потока газоконденсата необходимо для точной оценки продуктивности скважин. Ряд лабораторных экспериментов демонстрирует, что относительная проницаемость газоконденсата возрастает при больших скоростях, уменьшая негативное влияние газоконденсатной пробки на продуктивность скважин. С другой стороны, инерционные эффекты потока могут уменьшить эффективную проницаемость газа и, соответственно, продуктивность скважины. В этой работе представлены результаты измерений относительной проницаемости на слабо проницаемом стержне из песчаника, используя пятикомпонентную газоконденсатную смесь. В экспериментах использовался квазиравно- 
весный метод при высоких давлениях и скоростях, условия измерений были сходны с таковыми в месторождении вблизи скважины. После проведения измерений для набора межповерхностных натяжений и скоростей результаты могут быть использованы для оценки эффектов потоков с высоким числом капиллярности и инерционностью и для количественного исследования влияния этих двух конфликтующих явлений. Согласно экспериментальным данным, коэффициент инерционного потока на $50 \%$ выше, чем в эквивалентной 2-фазовой системе из газа и воды.

Результаты этих экспериментов были моделированы через корреляцию относительной проницаемости от числа капиллярности, одновременно с поправкой к относительной проницаемости за счет инерционности потока. В работе обсуждаются эти модели и показывается, как они могут быть использованы для поведения скважины в полностью аналогичной реальной модели месторождения.

Определение относительных фазовых проницаемостей в случае трехфазной фильтрации является значительно более сложной задачей и соответствующие эксперименты проводятся достаточно редко. Практически фазовые проницаемости для трехфазной системы определяют по данным двухфазной фильтрации. Наибольшее распространение получили модели, предложенные в работах $[30,31,32]$. Фазовые проницаемости зависят только от соответствующей насыщенности и определяются по данным двухфазной фильтрации. Для простоты предполагается, что газонасыщенность защемленным газом равна нулю, т.е. газ вытесняется полностью.

В работе [33] рассматриваются методы борьбы с конденсатными пробками. Эффект выпадения конденсата при добыче газа - одна из главных сушествуюших проблем. Когда пластовое давление падает ниже давления точки росы при эксплуатации месторождения, жидкая фаза выпадает из газовой фазы и образует конденсат в пласте. Есть два сценария, которые могут привести к падению давления. Одним из них является падение давления из-за добычи пластовой жидкости. Пластовая жидкость вытекает из пласта высокого давления к сепараторам на поверхности с более низким давлением. Второй сценарий - падение пластового давления из-за истощения. Во время добычи газа и конденсата пластовое давление будет уменьшаться со временем и, когда оно падает ниже давления точки росы, конденсат выпадает в жидкую фазу в пласте. Конденсат значительно уменьшает проницаемость газа. Следовательно, это снижает производительность добычи газа. Для решения этой проблемы было предложено несколько методов: закачка газа, обработка $\mathrm{CO}_{2}$, изменение смачиваемости, уменьшение межфазного натяжения, гидроразрыв пласта и нетрадиционные скважины. Некоторые из этих методов были реализованы на месторождениях и показали положительные результаты, но каждый метод имеет преимущества и недостатки, которые необходимо изучить далее в целях повышения его эффективности. 
В работе [34] описано явление образования конденсата, а также представлены уравнения состояния, которые могут предсказывать конденсацию газа. В статье [35] исследовались эмпирические корреляции давления точки росы и давления образования пузырей. Это накопление конденсата, известное как конденсатная пробка, вызывает уменьшение относительной проницаемости газа, следовательно, дебит скважины резко падает. Например, продуктивность на месторождении в Калифорнии значительно уменьшилась вследствие двойственного влияния конденсатной пробки и высокой водонасыщенности [36]. Добыча на месторождении Cal Canal составляла только 10\% от первоначального значения. Другой пример, месторождение Арун в Индонезии, где производительность скважины снизилась более чем в два раза за счет влияния конденсатной пробки [37].

В процессе добычи и доставки продукции на пункты приема, давление пластовой жидкости может быть ниже давления точки росы. Подобная ситуация часто происходит в районе ствола скважины. Был проведен ряд исследований, направленных на рассмотрение этого случая, которые показали, что переход от однофазного к многофазному течению около скважины приводит к образованию скопления конденсата. Согласно [38] когда конденсат образуется вблизи ствола скважины, он создает три различные области подвижности в резервуаре. В области, где давление жидкости еще выше давления точки росы, есть только одна газовая фаза. В зонах, где давление жидкости ниже, чем давление точки росы, присутствуют две фазы: газ и конденсат. В одной области конденсат неподвижен, потому что насыщенность конденсата ниже критического значения.

С другой стороны, в прискважинной области конденсат мобилен и поступает вместе с газом к скважине, потому что насыщенность конденсата выше критического насыщения. Эти две области являются областями выпадения конденсата, поэтому важно изучить поведение флюидов в этих двух областях, чтобы иметь возможность смягчения последствий выпадения конденсата. Было предложено несколько методов для смягчения последствий выпадения конденсата. Их можно сгруппировать в три различных подхода. Первый подход направлен на сохранение давления в пласте выше давления точки росы на основе использования газового рецикла или закачки $\mathrm{CO}_{2}$. Методы второго подхода нацелены на увеличение подвижности конденсата в районе ствола скважины, чтобы заставить его течь с газом к стволу скважины. Обеспечить это можно изменением смачиваемости или уменьшением межфазного натяжения. Наконец, третий подход состоит в том, чтобы уменьшить падение давления и тем самым задержать время достижения давления точки росы, используя гидроразрыв или горизонтальные скважины. Рассмотрим более подробно методы, относящиеся к указанным трем группам. 
Методы, направленные на сохранение давления

\section{в nлlacme}

Закачка сухого газа является одним из самых распространенных методов предотвращения выпадения конденсата. При таком методе сохраняется давление в резервуаре выше давления точки росы, что способствует вытеснению ценного конденсата из пласта [39]. Также, если выпавший конденсат уже существовал в пласте, закачка газа способствует повторному испарению конденсата [40]. Хотя газовый рецикл является очень эффективным методом снижения выпадения конденсата и образования конденсатной пробки, однако увеличение потребления газа приводило к увеличению стоимости добываемой продукции, что побудило ученых найти альтернативу для этого метода. Farzad и др. изучали стратегии добычи пластовых флюидов при закачки смешиваюших и несмешивающих газов [41]. Rostami и др. изучали возможность закачки смешивающегося газа в карбонатный пласт [42]. Углекислый газ, чистый метан и азот рассмотрены как альтернатива для сухого газа. Авторы работы [43] доказали в своих исследованиях, что закачка углекислого газа существенно увеличивает извлечение конденсата, что обусловлено тем, что предотвращается накопление конденсата в течение определенного времени.

Азот является хорошим газом для закачки, так как это дешевый, некоррозионный и чистый газ. Однако, есть некоторые вопросы, связанные с использованием азота. Хотя закачка азота увеличивает извлечение конденсата, он не так эффективен, как закачка углекислого газа, метана и газовый рецикл. Так был провен эксперимент, чтобы показать, что метан испаряет жидкую фазу при меньшем количестве закачки (55\% моль), чем при закачке азота (98\%) [44]. Исследование также показало, что закачанный азот может смешиваться с газовым конденсатом в пласте и давление точки росы смеси выше, чем начальное давление точки росы на месторождении. В результате увеличивается выпадение конденсата в пласте. Углекислый газ очень эффективен при добыче газа. Эффективность закачки углекислого газа почти такая же, как природного газа.

При более низких пластовых давлениях впрыск углекислого газа приводит к более высокой скорости восстановления добычи газа по сравнению с закачкой природного газа. Однако углекислый газ менее эффективен при восстановлении дебита конденсата по сравнению с природным газом. Поэтому необходимы дальнейшие исследования закачки углекислого газа для повышения эффективности извлечения конденсата. Преимушество закачки газа в том, что она может смягчить проблему выпадения конденсата внутри пласта. Закачку газа можно использовать для предотвращения образования конденсата в пласте путем поддержания пластового давления выше давления точки росы, или закачка газа может разрешить проблему закупорки конденсата, когда конденсат уже образовался в пласте. Он будет повторно пе- 
реведен в газовую фазу, что обеспечит его перемещение к скважине. Однако недостатком этого метода является то, что необходимо большое количество закачиваемого газа.

В статье [45] рассматривается метод теплового воздействия на пласт с целью увеличения дебита добывающей скважины и приводятся результаты физического и математического моделирования теплового воздействия на модель пласта. Проведенные теоретические и экспериментальные исследования показали возможность увеличения дебита высококипящего компонента при тепловом воздействии на призабойную зону газоконденсатного пласта. Термическое воздействие на прискважинную зону может быть применено как метод повышения коэффициента извлечения газового конденсата. Разработанные математическая и физическая модели пласта могут быть использованы для исследования процессов фильтрации многокомпонентных двухфазных углеводородных смесей и методов воздействия на эти процессы. Очевидно, что применение той или иной схемы разработки месторождения с воздействием на пласт позволит дополнительно извлечь некоторую часть остаточных запасов газа и конденсата. В статье рассматриваются некоторые результаты работ, посвященных решению вопросов максимально полного извлечения газа из продуктивных пластов. В качестве дополнительных результатов можно отметить следующее:

1. По результатам расчетов на секторной гидродинамической модели в вариантах с закачкой азота ожидается не только прирост в добыче конденсата на 40-50\% относительно базового варианта разработки, но и небольшой прирост в добыче сухого газа.

2. В Вачестве рекомендуемого сценария закачки азота выделяется вариант с соотношением нагнетательных и добывающих скважин 1/2, компенсация добычи закачкой $-100 \%$.

3. Проработана концепция обустройства наземного оборудования, обеспечивающего обратную закачку в пласт газа; капитальные затраты учтены в экономических расчетах.

4. Подтверждена эффективность закачки азота и на более поздних этапах разработки месторождения.

Технология сайклинг-процесса заключается в закачке сухого углеводородного газа для частичного поддержания пластового давления. Причем при содержании фракции $\mathrm{C} 2$ - C4, меньшем двукратного содержания стабильного конденсата (C5+), перед закачкой сухого углеводородного газа в пласте создается оторочка объемом не менее $15 \%$ объема пор зоны воздействия из углеводородного газа, насыщенного фракцией $\mathrm{C} 2$ - C4 при текущих пластовых давлениях и температурах. 
Рассматриваются также методы закачки воды или инертного газа по контуру месторождения с целью поддержания пластового давления на закритическом уровне, однако распространения они не получили.

Из физических методов исследуются взрывные, акустические и электромагнитные способы воздействия. При воздействии взрывом по пласту бурятся протяженные горизонтальные скважины, и по всей их длине укладывается в сплошной оболочке взрывчатое вещество с обеспечением энергии взрыва на единицу длины скважины от 15 до $60 \mathrm{MДж/м.}$

Предлагаются различные тепловые методы, обладающие наибольшей эффективностью при добыче газоконденсата. Их суть сводится к помещению источника тепла непосредственно на забой скважины и нагрев последнего до определенной температуры. В этом случае удается избежать непроизводительных потерь тепла, возникающих, например, при подаче тепла с поверхности.

Термобарохимическая технология обработки (ТБХО) заключается в использовании пороховых (твердотопливных) зарядов, не вызывающих повреждения забоя скважин. Сжигание заряда производится в течение длительного времени (до 0,5 ч), обеспечивающего оптимальное и эффективное воздействие на призабойную зону пласта. В технологии ТБХО сведены в один комплекс три метода обработки скважин: метод термогазохимического воздействия с использованием пороховых зарядов, химического воздействия, методы гидроимпульсного и депрессионного воздействия с использованием различных взрывных устройств. Мощность заряда, длительность горения и необходимые для успешной обработки скважин величины давлений и температур в призабойной зоне для конкретного месторождения определялись разработчиками технологии эмпирическим путем.

Закачка $\mathrm{CO}_{2}$ методом Huff-n-Puff аналогична использованию закачки углекислого газа для интенсификации добычи газа, где $\mathrm{CO}_{2}$ используется для вытеснения природного газа и конденсата, для увеличения дебита. Однако в технологии Huff-n-Puff $\mathrm{CO}_{2}$ закачивается непосредственно при эксплуатации месторождения, а затем скважина закрывается, чтобы позволить $\mathrm{CO}_{2}$ взаимодействовать с пластовой жидкостью и конденсатом в течение определенного периода времени [46]. Исследование Odi показало, что $\mathrm{CO}_{2}$ образует смесь с пластовой жидкостью и приводит к снижению давления точки росы в пласте. В результате, вновь испарившийся конденсат вместе с потоком $\mathrm{CO}_{2}$ направляется назад к скважине. Исследование показало, что концентрация $\mathrm{CO}_{2}$ увеличивается и давление точки росы уменьшается. Этот метод эффективен при достижении максимального уровня выпадения жидкой фазы [47].

Однако этот метод характеризуется кратким периодом воздействия, потому что после добычи начинается период, когда конденсат вновь выпадает в жидкой фазе вследствие повышения давления точки росы в текущей газовой смеси. Метод эффективен только при образовании конденсата вблизи ствола 
скважины. Если конденсат образуется внутри резервуара, этот метод не так эффективен, потому что его эффективный радиус очень ограничен. Преимуществом этого метода является то, что используется меньшее количество закачиваемого $\mathrm{CO}_{2}$ по сравнению с полной закачкой $\mathrm{CO}_{2}$.

\section{Методы, направленные на увеличение подвижности конденсата}

Когда выпавший конденсат формируется около скважины, конденсат в этой области находится в полной неподвижности. Если обеспечить подвижность конденсата, он будет течь с газовой фазой в пласте к стволу скважины; следовательно, относительная проницаемость газа увеличивается, и добыча возрастает. Для того чтобы достигнуть этого результата, можно использовать сурфактант для изменения смачиваемости пласта жидкой фазой вплоть до мокрого газа. Этот метод известен как изменение смачиваемости. Li и Firoozabidi успешно использовали химикаты FC759 и FC722 для изменения смачиваемости образца породы пласта [48]. Более позднее исследование Fahes, M., Firoozabadi, A. показало, что эти химические решения не эффективны при максимальной пластовой температуре [49]. Кроме того, эти химические реагенты дороги, поэтому этот метод пока использовать нецелесообразно при добыче газа. Li и др. изучали различные растворители для того, чтобы найти такой, который экономичен и стабилен при высоких пластовых температурах [50]. Они нашли WA12 как потенциальное решение для выпавшего конденсата. Этот реагент термически стабилен при $170{ }^{\circ} \mathrm{C}$ и в 20 раз дешевле химических реагентов, которые использовали Li и Firoozabidi. В то же время другое исследование, показало, что спирт 21-NE-06 и ингибированное дизельное топливо эффективны для удаления конденсатной пробки и увеличения эффективной газовой проницаемости [51].

Другой способ повышения подвижности выпавшего конденсата заключается в уменьшении капиллярного давления, которое проявляет конденсат в ловушке в пласте. По словам Al-Anazi и др., капиллярное давление может быть уменьшено путем уменьшения межфазное натяжение [52]. Растворители, такие как спирт, могут использоваться для уменьшения межфазного натяжения и извлечения конденсата с помощью многоконтактного смешивающегося вытеснения. Сообщается о нескольких случаях успешного применения реагентов на основе спирта в полевых условиях. После первых четырех месяцев обработки метанолом, продуктивность на месторождении Hatter's Pond field увеличилась в 2 раза [53].

На месторождении Cupiagua использовались ингибированные дизельные и спиртовые смеси для проведения стимулирующих процедур для уменьшения влияния выпавшего конденсата на протяжении нескольких лет. Однако, этот метод может только временно уменьшить влияние конденсата, и после короткого периода после обработки, конденсат начинает скапливаться снова внутри пласта [54]. 
Методы, направленные на замедление падения давления

Известно, что гидроразрыв пласта очень эффективен для уменьшения влияния выпавшего конденсата, потому что он увеличивает зону контакта скважины с пластом и снижает темп падения пластового давления в прискважинной области [55]. Однако, этот метод только задерживает время достижения давления точки росы, но не предотвращает закупорку конденсата, а следовательно, не исключает накопление конденсата в районах, где давление в пласте ниже давления точки росы.

Miller N., Nasrabadi, H., Zhu, D. в своем исследовании показали, что просадка давления для горизонтальной скважины намного меньше, чем для вертикальной скважины [56]. Поэтому давление на забое горизонтальной скважины достигнет давления точки росы за более длительное время по сравнению с вертикальной скважиной. Кроме того, исследование показывает, что горизонтальная скважина уменьшает закупорку конденсата вблизи ствола скважины, потому что показатель продуктивности в горизонтальной скважине остается почти таким же после того, как достигается давление точки росы. Несмотря на то, что была доказана эффективность использования горизонтальной скважины для уменьшения влияния выпавшего конденсата, такая скважина не предотвращает выпадения конденсата около ствола скважины. Кроме того, горизонтальная скважина дороже сопоставимой вертикальной скважины, поэтому необходимо сделать экономический расчет обоих вариантов.

\section{РЕЗУЛЬТАТЫ И ОБСУЖДЕНИЯ}

Россия обладает значительным углеводородным потенциалом. Суммарные прогнозные ресурсы страны оцениваются в 62.7 млрд. т. Большая часть этих ресурсов сосредоточена в восточных и северных районах страны, а также на шельфах арктических и дальневосточных морей. В настоящее время из 2223 открытых в России нефтяных, газонефтяных и газоконденсатных месторождений в разработку вовлечено 1191, а запасы эксплуатируемых месторождений выработаны в среднем на 45\%. Около $80 \%$ доказанных запасов сосредоточено в районах суши с развитой добывающей структурой. При этом, в настоящее время значительная часть крупнейших залежей в России находится в стадии падающей добычи, с усугубляющейся тенденцией недоизвлекаемости углеводородного сырья.

На территории России сосредоточено около 1/3 разведанных мировых запасов природного газа, потенциальные запасы которого оцениваются в 62,7 млрд. т., из них на европейскую часть приходится $11,6 \%$, а на восточные районы - 84,4\%, на шельф внутренних морей - 0,5\%. Свыше $90 \%$ природного газа добывается в Западной Сибири, в том числе $87 \%$ - в Ямало-Ненецком и $4 \%-$ в Ханты-Мансийском автономных округах. Здесь расположены крупнейшие 
месторождения: Уренгойское, Ямбургское, Заполярное, Медвежье и др. Промышленные запасы природного газа этого региона составляют более $60 \%$ всех ресурсов страны. Среди других газодобывающих территорий выделяются Урал (Оренбургское газоконденсатное месторождение - более 3\% добычи), Северный район (Вуктылское месторождение). Есть ресурсы природного газа в Нижнем Поволжье (Астраханское газоконденсатное месторождение), на Северном Кавказе (Северо-Ставропольское, Кубано-Приазовское месторождения), на Дальнем Востоке (Усть-Вилюйское, Тунгор на о. Сахалин). Чаяндинское нефтегазоконденсатное месторождение - одно из крупнейших на востоке России. Является базовым для формирования Якутского центра газодобычи и ресурсной базой для газопровода «Сила Сибири». Открыто в 1983 году. Расположено в Ленском районе Якутии. Балансовые запасы оцениваются в 1240 млрд $\mathbf{m}^{3}$.

Проведение фундаментальных теоретических и экспериментальных исследований свойств газоконденсатных систем в пластах и разработка методов воздействия на эти системы с целью повышения конденсатоотдачи является актуальной задачей. По величине проектного коэффициента извлечения конденсата (КИК) почти 50\% запасов конденсата связано с объектами, для которых КИК утвержден в диапазоне от 0,6 до 0,7 , еще для $25 \%$ - ниже 0,6 . Проектный коэффициент извлечения резко снижается по мере роста содержания конденсата. В настоящее время мировой тренд развития в газовой науке - это разработка передовых математических моделей с учетом новых, более тонких физических эффектов, влияющих на характерные качественные показатели процессов доизвлечения. Проблема увеличения КИК при разработке ГКМ и НГКМ стоит во всех газодобывающих странах мира. В процессе разработки ГКМ и НГКМ на естественном режиме пластовое давление снижается, и, в результате ретроградной конденсации и различных фазовых проницаемостей газовой и жидкой фаз, ретроградный конденсат становится неподвижным в пористой среде пласта, что приводит к нарушению режимов работы добывающих скважин и снижению КИК.

На практике известны режимы неустойчивости работы реальных газоконденсатных месторождений, которые наблюдаются при их эксплуатации. Такое поведение характерно для газоконденсатных смесей, имеющих фазовую диаграмму с ретроградной областью и функциями фазовых проницаемостей специального вида (наличием нулевых значений для определенных величин газо- и влагонасыщенностей). Известны экспериментальные и теоретические результаты, показывающие возможность существования периодических решений задачи фильтрации газоконденсатных смесей в пористой среде. Требуются дальнейшие исследования газоконденсатной смеси в процессе фильтрации как колебательной системы, что позволит использовать методы расчета колебательных систем с целью определения их основных характеристик (в первую очередь, собственных частот) для эффективного 
внешнего воздействия на резонансных частотах с целью повышения КИК и выхода газовой и жидкой фаз.

Особенностью воздействия на газоконденсатный пласт обогащенного газа является то, что получающаяся в результате смешивания пластового и нагнетаемого флюидов система сушественно приближается к критической точке. Для фильтрационных расчетов процессов такого типа весьма существенным является корректное задание функции относительной фазовой проницаемости (ОФП). При подходе к критическому состоянию должно иметь место асимптотическое стремление коэффищиентов ОФП к самим насышенностям. Это также означает, что существует необходимость введения явной (аналитической) зависимости ОФП от составов фаз. Этого можно достичь лишь на основе совместных экспериментально-теоретических исследований в околокритической области и проведения математического моделирования и физического эксперимента на линейной модели пласта. В эксперименте модель пласта заполняется пластовой углеводородной жидкой фазой, которая должна вытесняться равновесной к ней газовой фазой до исчезновения жидкости в выходящем потоке. Далее, на втором этапе эксперимента через модель пласта производится прокачка обогашенного газа. Математическая модель должна показать, что перед началом второго этапа эксперимента распределение концентраций и насыщенностей по пласту существенно неоднородно и что моделирование процесса без подготовки и проведения первой стадии эксперимента, начиная сразу со второй стадии, искажает результаты. Необходимо провести сравнение расчетных и экспериментальных зависимостей среднепластовой насыщенности на первой стадии эксперимента, плотности жидкой фазы в выходной части модели пласта. Таким образом, учет околокритических перестроек функций ОФП существенен при математическом моделировании фильтрации смешивающихся многофазных флюидов.

Необходимо также вычисление бифуркационных значений параметров, характеризующих процесс фильтрации, при которых происходит ветвление решений и смена стационарного режима на автоволновой, теоретическое определение времён релаксации. При этом необходимо установление связи наблюдаемых в эксперименте неустойчивостей с типичными особенностями фазовых диаграмм многокомпонентных смесей - верификация теории и эксперимента. Условия неустойчивости эквивалентны условиям нахождения системы в области ретроградной конденсации, поэтому существует связь ретроградных явлений с так называемым эффектом отрицательного объема тяжелых компонентов. Эти явления прямо связаны с отрицательной сжимаемостью индивидуального объема фильтрующегося двухфазного континуума, что и приводит к неустойчивости. При математическом описании гидродинамики двухфазной смеси в пористой среде в области ретроградной конденсации должна быть учтена возможность падающей ветви плотности смеси, и требуется соответствующая экспериментальная проверка. 
Хотя было предложено несколько методов для смягчения воздействия выпавшего конденсата, таких как закачка газов, $\mathrm{CO}_{2}$ Huff-n-Puff, изменение смачиваемости, снижение межфазного натяжения, гидроразрыв пласта и горизонтальные скважины, многие из них имеют свои недостатки, когда дело доходит до их практического применения на месторождении. Для закачки газа обычно используется природный газ и показывает лучшие результаты по сравнению с другими газами, такими как метан, углекислый газ или азот. Однако для его использования необходимо большое количество природного газа при полном масштабе закачки. Закачка углекислого газа методом Huff-NPuff - кратковременный метод стимуляции, потому что после короткого периода обработки, выпадение конденсата происходит интенсивней, поскольку текущая газовая смесь возвращает пластовое давление к более высокому давлению точки росы. Изменение смачиваемости и снижение межфазного натяжения показали многообешающий результат с точки зрения уменьшения влияния выпавшего конденсата, но такая обработка эффективна только, когда конденсат расположен около скважины, и не влияет извлекаемость конденсата на удалении от скважины внутри пласта. Гидравлический разрыв и горизонтальные скважины не экономичны. Они обеспечивают задержку времени достижения давления точки росы, но не предотвращают образования конденсатной пробки.

Газоконденсатные коллекторы демонстрируют сложное поведение потока ниже давления точки росы, вызванное изменением состава и созданием и ростом конденсата вокруг скважины, что снижает относительную проницаемость для газового потока [57]. Результаты этого исследования демонстрируют критическую важность эффектов выпадения жидкости в газоконденсатном месторождении.

\section{выводы}

При всем разнообразии условий добычи углеводородного сырья, для газоконденсата возможно выделить одно общее характерное физическое явление - выпадение конденсата в пласте. Например, объем выпавшего в залежи конденсата на Вуктыльском, Оренбургском, Астраханском, Уренгойском месторождениях оценивается в 70-100 млн тонн. Моделирование фильтрационных потоков дает возможность выделить основные физические процессы, влияющие на фильтрацию смеси, оценить их численно, и, в конечном итоге, разработать методы воздействия на газоконденсатную систему для повышения эффективности эксплуатации месторождения. В частности, повышение производительности действующей скважины может быть основано на явлении понижения давления начала конденсации газоконденсата при увеличении в его составе углеводородов «пентан + высшие». Для этого в зоне перфорации добывающей скважины устанавливают регулируемый ультрафильтр, задерживающий эту фракцию. Таким образом, понижается давление 
начала конденсации газоконденсата, что позволяет эксплуатировать скважину с большими депрессиями и, следовательно, с большим дебитом.

Различные сценарии эксплуатации месторождений могут скорректировать состав извлекаемой продукции и количество выпадающего конденсата в пласте. С учетом понимания того, как меняется состав и количество извлекаемых флюидов и выпавшего конденсата в зависимости от стратегии добычи, можно добиться улучшения показателей по добыче из газоконденсатных пластов.

\section{Благодарности \\ Работа выполнена при финансовой поддержке гранта РФФИ (грант № 17-08-01270A).}

\section{Библиографический список}

1. Шестаков В.М. Динамика подземных вод. М.: Изд-во МГУ, 1973. $328 \mathrm{c}$.

2. Тер-Саркисов. Гидротермодинамическое моделирование активных методов разработки ГКМ // Нефтегазовое дело, 2015, т.13, №2, С. 68-73.

3. А.Э. Конторович. Пути освоения ресурсов нефти и газа российского сектора Арктики // Вестник Российской академии наук. 2015. T. 85. № 5-6. С. 420-430.

4. Вяхирев Р.И., Гриценко А.И., Тер-Саркисов Р.М. Разработка и эксплуатация газовых месторождений. М.: Недра, 2002. 880 c.

5. Брусиловский А.И. Многокомпонентная фильтрация газоконденсатных систем в глубокопогруженных залежах // Oil and gas geology, 1997. N. 7. P. 31-38

6. Гриценко А.И., Ремизов В.В., Тер-Саркисов Р.М., Подюк В.Г., Николаев В.А., Шандрыгин А.Н. Руководство по восстановлению продуктивности газоконденсатных скважин. М.: ВНИИГАЗ, 1995. 65 c.

7. Жузе Т.П. Сжатые газы как растворители. М.: Наука, 1974. 112 c.

8. Намиот А.Ю. Фазовые превращения в добыче нефти. М.: Недра, 1976. 185 с.

9. Степанова Г.С. Фазовые превращения в месторождениях нефрти и газа. М.: Недра, 1983. 192 с.

10. Бузинов С.Н., Николаев В.А., Тер-Саркисов Р.М. Одно из направлений повышения отборов нефти и конденсата на объектах газодобывающей отрасли // Проблемы эксплуатации газовых скважин на месторождениях с осложненными горногеологическими условиями: сб. науч. тр. / ВНИИГАЗ. М., 1980. C. $31-40$.

11. Закачка жидких углеводородов в пласт для повышения нефртеконденсатоотдачи / А.И. Гриценко, Р.М. Тер-Саркисов, О.В. 
Клапчук, В.А. Николаев // Разработка и эксплуатация газовых и газоконденсатных месторождений: обзор, информ. М.: ВНИИЭГазпром, 1980. Вып. 6. С. 35-45.

12. Макаров Е. С. Исследование способов дополнительного извлечения газоконденсата из ачимовских пластов на гидродинамических моделях / Е.С. Макаров, А.Ю. Юшков, А.С. Романов // Вестник Тюменского государственного университета. Физикоматематическое моделирование. Нефть, газ, энергетика. 2017. Tом 3. № 1. С. 79-90.

13. Прогнозирование сайклинг-процесса с использованием модели Black oil / Закиров С.Н., Брусиловский А.И., Закиров Э.С., Карлинский Е.Д., Смирнов Б.В., Дорошенко Ю.Е., Федотова В.А. // Газовая промышленность. 1998. №7. С. 54-56.

14. «Скрытая» фильтрация ретроградного конденсата при нагнетании в пласт газообразного растворителя / Р.М. Тер - Саркисов и др. // Проблемы повышения углеводородоотдачи пласта газоконденсатныХ месторождений: сб. науч. тр. / ВНИИГАЗ. М., 1991. C. 3-11.

15. 15.Макеев Б.В., Кобилев В.А. Извлечение выпавшего конденсата из модели неоднородного пласта // Тр. ВНИИгаза: Проблемы повышения углево 405 дородоотдачи пласта газоконденсатных месторождений. М.: ВНИИгаз, 1995. С. 40-47.

16. Технология увеличения газоотдачи и утилизации пластовой воды / С.Н. Закиров, Э.С. Закиров, А.А. Огнев, В.Ф. Петин, Ю.М. Басарыгин, В.Ф. Будников, Р.М. Кондрат // Наука и технология углеводородов. 1999. № 2. С. 12-17.

17. Бураков Ю.Г., Гужов Н. А., Назаров А.В. Численная модель трехфазной фильтрации при водогазовом воздействии на газоконденсатный пласт / Проблемы повышения углеводородоотдачи пласта газоконденсатных месторождений. Тр. ВНИИгаза. - М.: ВНИИгаз, 1991. С. 58-65.

18. Тер-Саркисов Р.М. Использование обогащенного газа для повышения конденсатоотдачи // Газовая промышленность. 1982. № 10. С. 26-28.

19. Гриценко А.И., Николаев В.А., Тер-Саркисов Р.М. Компонентоотдача пласта при разработке газоконденсатных залежей. М.: Недра, 1995. 272 с.

20. Тер-Саркисов Р.М. Повышение углеводородоотдачи пласта нефтегазоконденсатных месторождений. М.: Недра, 1995. 167 с.

21. Al-Anazi, Hamoud, G. Walker, Jacob \& A. Pope, Gary \& Sharma, Mukul \& F. Hackney, David. A Successful Methanol Treatment in a Gas/condensate Reservoir: Field Application. SPE Production \& Facilities.2005. pp. 60-69.

22. Fan, L \& Harris, B.W. \& Jamaluddin, A.J. \& Kamath, J \& Mott, R \& Pope, G.A. \& Shandrygin, A \& Whitson, Curtis. Understanding gascondensate reservoirs. Oilfield Rev.. 2005, pp.16-25.

23. Vo, Hai \& Horne, Roland. Compositional Variation Study for Improving Recovery in Gas- Condensate Reservoirs. 2016.

24. Han Seah, Yong \& Gringarten, Alain \& Ann Giddins, Marie \& Burton, 
Kirsty. Optimising Recovery in Gas Condensate Reservoirs. 2014.

25. Булейко В.М. Закономерности фазовых превращений углеводородных смесей в нефтегазоностных пластах разрабатываемых месторождений (по экспериментальным данным): дис. ... на соискание ученой степени доктора тех.наук. М. 2007 г.

26. Henderson G. D., Danesh A., Tehrani D., Peden J. M. The Effect of Velocity and Interfacial Tension on the Relative Permeability of Gas Condensate Fluids in the Wellbore Region, Symposium in Vienna, Austria, May 15-17, 1995

27. Sanaei A., Jamili A., Callard J. University of Oklahoma, Mewbourne School of Petroleum and Geological Engineering, U.S.A. "Effects of non Darcy flow and pore proximity on gas condensate prodaction from nanopor unconventional resources", 2010, p. 505-520

28. Pingping Shen, Bin Zhu, Xian-Bin Li, Yu-Shu Wu An Experimental Study of the Influence of Interfacial Tension on Water-Oil TwoPhase Relative Permeability, Springer, 2010, p. 505-520

29. Huseyin Calisgan, Birol Demiral and Serhat Akin An experimental study of near critical gas codensate relative permeability of carbonates, International Symposium of the Society of Core Analysts held in Trondheim, Norway 12-16 September, 2006

30. Stone H.L. Estimation of three-phase relative permeability and residual oil data // J. Canad. Petrol. Technol. 1973. V. I2, № 4. P. 5361.

31. Stone H.L. Probability model for estimating three-phase relative permeability.// J. Petrol. Technol. 1970. V. 22, № 2. P. 214218.

32. Stone H.L. Rigorous black-oil pseudofunctions.// Paper SPE 21207. $-1991$.

33. Amani M., Nguyen N. An Overview of Methods to Mitigate Condensate Banking in Retrograde Gas. Advances in Petroleum Exploration and Development Vol. 9, No. 2, 2015, pp. 1-6

34. Hosein, R., Dawe, R. A., \& Amani, M. (2011). Peng- Robinson equation of state predictions for gas condensate before and after lumping. Journal of Advances in Petroleum Exploration and Development, 2(2), 41-46.

35. Moradi, B., Malekzadeh, E., Amani, M., Boukadi, F., \& Kharrat, R. (2010, June). Bubble point pressure empirical correlation. Paper presented at Trinidad and Tobago Energy Resources Conference, Port of Spain, Trinidad and Tobago.

36. Engineer, R. Cal Canal field, California:Case history of a tight and abnormally pressured gas condensate reservoir. Paper presented at the SPE California Regional Meeting, Bakersfield, CA. 1985, March

37. Afidick, D., Kaczorowski, N. J., Bette, S. Production performance of retrograde gas reservoir: A case study of Arun field. Paper presented at the SPE Asia Pacific Oil and Gas Conference, Melbourne, Australia. 1994, November.

38. Al-Yami, A. M., Gomez, F. A., Al Hamed, K. I., Al-Buali, M. H. A successful field application of a new chemical treatment in a fluid blocked well in Saudi Arabia. Paper presented at the SPE Saudi 
Arabia section Annual Technical Symposium and Exhibition, Khobar, Saudi Arabia. 2013, May.

39. Fan, L., Harris, B. W., Jamaluddin, A., Kamath, J., Mott, R.,Pope, G A., Whitson, C. H. Understanding gascondensate reservoirs. Oilfield Review, 2005, 17(4), 14-27.

40. Abel, W., Jackson, R. F., \& Wattenbarger, R. A. Simulation of a partial pressure maintenance gas cycling project with a compositional model, Carson Creek Field, Alberta. 1970JPT, 22(1), 38-46.

41. Farzad, I., Amani, M. An analysis of reservoir production strategies in miscible and immiscible gas injection projects. Advances in $\mathrm{Pe}-$ troleum Exploration and Development, 2012, 3(1), 1-15.

42. Rostami, R., Amani, M., Alipour, M. Feasibility study of miscible gas injection in a carbonate oil reservoir: A systematic experimental and simulation approach. Paper presented at the Abu Dhabi International Petroleum Conference and Exhibition (ADIPEC), Abu Dhabi, UAE. 2012, November

43. Amini, Sh., Aminshahidy, B., Afshar, M. Simulation study of enhanced condensate recovery in a gas-condensate reservoir. Iranian Journal of Chemical Engineering, 8(1), 3-14, 2011.

44. Siregar, S., Hagoort, J., Ronde, H. March Nitrogen Injection vs. Gas Cycling in Rich Retrograde Condensate-Gas Reservoirs. Paper presented at the International Meeting on Petroleum Engineering, Beijing, China, 1992.

45. Зайченко В.М., Качалов В.В., Майков И.Л., Сокол ГФ., Торчинский В.М. Математическое и физическое моделирование теплового воздействия на газоконденсатные системы. Вести газовой науки. Актуальные вопросы исследований пластовых систем месторождений углеводородов. М.: Газпром ВНИИГАЗ. 2013. Т. 1. Вып. 12. С. 66-72.

46. Odi, U. Analysis and potential of $\mathrm{CO} 2$ Huff-n-Puff for near wellbore condensate removal and enhanced gas recovery. Paper presented at the SPE Annual Technical. Conference and Exhibition, San Antonio, Texas. 2011, October.

47. Ahmed, T., Evans, J., Kwan, R., \& Vivian, T. Wellbore liquid blockage in gas-condensate reservoirs. Paper presented at the SPE Eastern Regional Meeting, Pittsburgh, PA. 1998, November.

48. Li, K., Firoozabadi, A. Experimental study of wettability alteration to preferential gas-wetness in porous media and its effect. SPE REE, 2000, 3(2), 139-149.

49. Fahes, M., \& Firoozabadi, A. Wettability alteration to intermediate gas-wetting in gas-condensate reservoirs at high temperatures 2005, October.

50. Liu, Y. J., Zheng, H. W., Li, G. X., Li, G. Q., Li, K. W. Improving production in gas/condensate reservoirs by wettability alteration to gas wetness.Paper presented at the SPE/DOE Symposium on Improved Oil Recovery, Tulsa, Oklahoma. 2006, April.

51. Alzate, G. A., Franco, C. A., Restrepo, A., Castrillon, J. J. P., Alvares, D. L. B., Murillo, A. A. E. Evaluation of alcohol-based treatments for condensate banking removal. Paper presented at the SPE Inter- 
national Symposium and Exhibition on Formation Damage Control, Lafayette, Louisiana. 2006, February.

52. Al-Anazi, A. H., Xiao, J. J., Al-Eidan, A. A., Buhidma, I. M.,Ahmed, M. S., Al-Faifi, M., Assiri, W. J. Gas productivity enhancement by wettability alteration of gas-condensate reservoirs. Paper presented at the European Formation Damage Conference, Scheveningen, the Netherlands. 2007, June.

53. Al-Anazi, H. A., Walker, J. G., Pope, G. A., Sharma, M. M., Hackney, D. F. A successful methanol treatment in a gas-condensate reservoir: Field application. Paper presented at the SPE Production and Operations Symposium, Oklahoma City, Oklahoma. 2003, March.

54. Franco, C.A., Romero, R.D.Z., Arango, J.F.Z., Mora, E., Botero, O.F., Candela, C.H., Mejia, A. F. C. Inhibited gas stimulation to mitigate condensate banking and maximize recovery in Cupiagua field. Paper presented at the SPE International Symposium and Exhibition on Formation Damage Control, Lafayette, Louisiana. 2012, February.

55. Ignatyev, A.E., Mukminov, I.R., Vikulova, E.A., Pepelyayev, R.V. Multistage hydraulic fracturing in horizontal wells as a method for the effective development of gas-condensate fields in the Arctic region. Paper presented at the SPE Arctic and Extreme Environments Conference \& Exhibition held in Moscow, Russia. 2011, October.

56. Miller N., Nasrabadi, H., Zhu, D. Application of horizontal wells to reduce condensate blockage in gas condensate reservoirs. Paper presented at the CPS/SPE International Oil and Gas Conference and Exhibition, Beijing, China. 2010, June.

57. Han Seah, Yong \& Gringarten, Alain \& Ann Giddins, Marie \& Burton, Kirsty. (2014). Optimising Recovery in Gas Condensate Reservoirs. 10.2118/171519-MS.

\section{References}

1. Shestakov V.M. Groundwater dynamics. M.: Publishing House of Moscow State University, 1973. 328 p.

2. Ter-Sarkisov. Hydrothermodynamic Modeling of Active Methods for the Development of GCM // Oil and Gas Business, 2015, v. 13, no. 2, p. 68-73.

3. A.E. Kontorovich. Ways of development of oil and gas resources of the Russian sector of the Arctic // Bulletin of the Russian Academy of Sciences. 2015. T. 85. № 5-6. Pp. 420-430.

4. Vyakhirev R.I., Gritsenko A.I., Ter-Sarkisov R.M. Development and operation of gas fields. M.: Nedra, 2002. 880 p.

5. Brusilovsky A.I. Multicomponent filtration of gas condensate systems in deep-lying deposits // Oil and gas geology, 1997. №7. P. 31-38.

6. Gritsenko A.I., Remizov V.V., Ter-Sarkisov P.M., Podyuk V.G., Nikolaev V.A., Shandrygin A.N. Guidelines for the recovery of gas condensate wells. M.: VNIIGAZ, 1995. 65 p.

7. Joseph ETC. Compressed gases as solvents. M.: Science, 1974. $112 \mathrm{p}$. 
8. Namiot A.Yu. Phase transformations in oil production. M.: Nedra, 1976. $185 \mathrm{p}$.

9. Stepanova G.S. Phase transformations in oil and gas fields. $-M$.: Nedra, 1983.-192 p.

10. Buzinov S.N., Nikolaev V.A., Ter-Sarkisov P.M. One of the ways to increase the extraction of oil and condensate at the gas industry facilities // Problems of operation of gas wells in fields with complicated mining and geological conditions: Coll. scientific tr. / VNIIGAZ. M., 1980. S. 31-40.

11. Injection of liquid hydrocarbons into the reservoir to increase oil condensate recovery / A.I. Gritsenko, P.M. Ter-Sarkisov, O.V. Klapchuk, V.A. Nikolaev // Development and operation of gas and gas condensate fields: review, inform. M.: VNIIEGazprom, 1980. Vol. 6. From 35-45.

12. E. Makarov. Study of methods for additional extraction of gas condensate from Achimov formations on hydrodynamic models / E.S. Makarov, A. Yu. Yushkov, A. S. Romanov // Tyumen State University Bulletin. Physical and mathematical modeling. Oil, gas, energy. 2017. Volume 3. № 1. P. 79-90.

13. Prediction of a cycling process using the Black oil model / Zakirov S.N., Brusilovsky A.I., Zakirov E.S., Karlinsky E.D., Smirnov B.V., Doroshenko Yu. E., Fedotova V. .BUT. // Gas industry. 1998. №7. WITH . 54-56.

14. "Hidden" filtration of retrograde condensate when a gaseous solvent is injected into the formation / P.M. Ter - Sarkisov and others. // Problems of increasing the hydrocarbon recovery of a reservoir from gas condensate fields: collection of papers. scientific tr. / VNIIGAZ. M. 1991. p. 3-11.

15. Makeev B.V., Kobilev V.A. Removing Condensate from the Inhomogeneous Formation Model, Tr. VNIlgaza: Problems of increasing coal recovery of gas condensate fields. M.: VNIIgaz, 1995. p. 40-47.

16. Technology for increasing gas recovery and utilization of formation water / S.N. Zakirov, E.S. Zakirov, A.A. Ognev, V.F. Petin, Yu.M. Basarygin, V.F. Budnikov, P.M. Kondrat // Science and technology of hydrocarbons. 1999. № 2. p. 12-17.

17. Burakov Yu.G., Guzhov N.A., Nazarov A.V. Numerical model of three-phase filtration in the case of water-gas impact on a gascondensate reservoir / Problems of increasing the hydrocarbon recovery of a formation of gas-condensate fields. Tr. VNligaz. M.: VNIlgaz, 1991. pp. 58-65.

18. Ter-Sarkisov P.M. Use of enriched gas to increase condensate recovery // Gas industry. 1982. № 10. p. 26-28.

19. Gritsenko A.I., Nikolaev V.A., Ter-Sarkisov P.M. Component recovery in the development of gas condensate deposits. - M.: Nedra, 1995. - $272 p$.

20. Ter-Sarkisov P.M. Increased hydrocarbon recovery of oil and gas condensate fields. M.: Nedra, 1995. $167 \mathrm{p}$.

21. Al-Anazi, Hamoud, G. Walker, Jacob \& A. Pope, Gary \& Sharma, Mukul \& F. Hackney, David. A Successful Methanol Treatment in 
a Gas/condensate Reservoir: Field Application. SPE Production \& Facilities.2005. pp. 60-69.

22. Fan, L \& Harris, B.W. \& Jamaluddin, A.J. \& Kamath, J \& Mott, R \& Pope, G.A. \& Shandrygin, A \& Whitson, Curtis. Understanding gascondensate reservoirs. Oilfield Rev.. 2005, pp.16-25.

23. Vo, Hai \& Horne, Roland. Compositional Variation Study for Improving Recovery in Gas- Condensate Reservoirs. 2016.

24. Han Seah, Yong \& Gringarten, Alain \& Ann Giddins, Marie \& Burton, Kirsty. Optimising Recovery in Gas Condensate Reservoirs. 2014.

25. Buleiko V.M. Patterns of phase transformations of hydrocarbon mixtures in oil and gas reservoirs of the developed fields (according to experimental data). Diss. for the degree of doctor of technical science. M. 2007

26. Henderson G. D., Danesh A., Tehrani D., Peden J. M. The Effect of Velocity and Interfacial Tension on the Relative Permeability of Gas Condensate Fluids in the Wellbore Region, Symposium in Vienna, Austria, May 15-17, 1995

27. Sanaei A., Jamili A., Callard J. University of Oklahoma, Mewbourne School of Petroleum and Geological Engineering, U.S.A. "Effects of non Darcy flow and pore proximity on gas condensate prodaction from nanopor unconventional resources", 2010, p. 505-520

28. Pingping Shen, Bin Zhu, Xian-Bin Li, Yu-Shu Wu An Experimental Study of the Influence of Interfacial Tension on Water-Oil TwoPhase Relative Permeability, Springer, 2010, p. 505-520

29. Huseyin Calisgan, Birol Demiral and Serhat Akin An experimental study of near critical gas codensate relative permeability of carbonates, International Symposium of the Society of Core Analysts held in Trondheim, Norway 12-16 September, 2006

30. Stone H.L. Estimation of three-phase relative permeability and residual oil data.// J. Canad. Petrol. Technol. 1973. V. I2, № 4. P. 5361.

31. Stone H.L. Probability model for estimating three-phase relative permeability.// J. Petrol. Technol. 1970. V. 22, № 2. P. 214218.

32. Stone H.L. Rigorous black-oil pseudofunctions // Paper SPE 21207. 1991

33. Amani M., Nguyen N. An Overview of Methods to Mitigate Condensate Banking in Retrograde Gas. Advances in Petroleum Exploration and Development Vol. 9, No. 2, 2015, pp. 1-6

34. Hosein, R., Dawe, R. A., \& Amani, M. (2011). Peng- Robinson equation of state predictions for gas condensate before and after lumping. Journal of Advances in Petroleum Exploration and Development, 2(2), 41-46.

35. Moradi, B., Malekzadeh, E., Amani, M., Boukadi, F., \& Kharrat, R. (2010, June). Bubble point pressure empirical correlation. Paper presented at Trinidad and Tobago Energy Resources Conference, Port of Spain, Trinidad and Tobago.

36. Engineer, R. Cal Canal field, California:Case history of a tight and abnormally pressured gas condensate reservoir. Paper presented 
at the SPE California Regional Meeting, Bakersfield, CA. 1985, March.

37. Afidick, D., Kaczorowski, N. J., Bette, S. Production performance of retrograde gas reservoir: A case study of Arun field. Paper presented at the SPE Asia Pacific Oil and Gas Conference, Melbourne, Australia. 1994, November.

38. Al-Yami, A. M., Gomez, F. A., Al Hamed, K. I., Al-Buali, M. H. A successful field application of a new chemical treatment in a fluid blocked well in Saudi Arabia. Paper presented at the SPE Saudi Arabia section Annual Technical Symposium and Exhibition, Khobar, Saudi Arabia. 2013, May

39. Fan, L., Harris, B. W., Jamaluddin, A., Kamath, J., Mott, R.,Pope, G A.,Whitson, C. H. Understanding gascondensate reservoirs. Oilfield Review, 2005, 17(4), 14-27.

40. Abel, W., Jackson, R. F., \& Wattenbarger, R. A. Simulation of a partial pressure maintenance gas cycling project with a compositional model, Carson Creek Field, Alberta. 1970.JPT, 22(1), 38-46.

41. Farzad, I., Amani, M. An analysis of reservoir production strategies in miscible and immiscible gas injection projects. Advances in Petroleum Exploration and Development, 2012, 3(1), 1-15.

42. Rostami, R., Amani, M., Alipour, M. Feasibility study of miscible gas injection in a carbonate oil reservoir: A systematic experimental and simulation approach. Paper presented at the Abu Dhabi International Petroleum Conference and Exhibition (ADIPEC), Abu Dhabi, UAE. 2012, November

43. Amini, Sh., Aminshahidy, B., Afshar, M. Simulation study of enhanced condensate recovery in a gas-condensate reservoir. Iranian Journal of Chemical Engineering, 8(1), 3-14, 2011.

44. Siregar, S., Hagoort, J., Ronde, H. March Nitrogen Injection vs. Gas Cycling in Rich Retrograde Condensate-Gas Reservoirs. Paper presented at the International Meeting on Petroleum Engineering, Beijing, China, 1992.

45. Zaichenko V.M., Kachalov V.V., Maikov I.L., Sokol GF, Torchinsky V.M. Mathematical and physical modeling of thermal effects on gas condensate systems. Lead gas science. Topical issues of studies of reservoir systems of hydrocarbon deposits. M.: Gazprom VNIIGAZ. - 2013. - V. 1. - Vol. 12. - p. 66-72.

46. Odi, U. Analysis and potential of $\mathrm{CO} 2$ Huff-n-Puff for near wellbore condensate removal and enhanced gas recovery. Paper presented at the SPE Annual Technical. Conference and Exhibition, San Antonio, Texas. 2011, October.

47. Ahmed, T., Evans, J., Kwan, R., \& Vivian, T. Wellbore liquid blockage in gas-condensate reservoirs. Paper presented at the SPE Eastern Regional Meeting, Pittsburgh, PA. 1998, November.

48. Li, K., Firoozabadi, A. Experimental study of wettability alteration to preferential gas-wetness in porous media and its effect. SPE REE, 2000, 3(2), 139-149.

49. Fahes, M., \& Firoozabadi, A. Wettability alteration to intermediate 
gas-wetting in gas-condensate reservoirs at high temperatures. 2005, October.

50. Liu, Y. J., Zheng, H. W., Li, G. X., Li, G. Q., Li, K. W. Improving production in gas/condensate reservoirs by wettability alteration to gas wetness. Paper presented at the SPE/DOE Symposium on Improved Oil Recovery, Tulsa, Oklahoma. 2006, April.

51. Alzate, G. A., Franco, C. A., Restrepo, A., Castrillon, J. J. P., Alvares, D. L. B., Murillo, A. A. E. Evaluation of alcohol-based treatments for condensate banking removal. Paper presented at the SPE International Symposium and Exhibition on Formation Damage Control, Lafayette, Louisiana. 2006, February.

52. Al-Anazi, A. H., Xiao, J. J., Al-Eidan, A. A., Buhidma, I. M.,Ahmed, M. S., Al-Faifi, M., Assiri, W. J. Gas productivity enhancement by wettability alteration of gas-condensate reservoirs. Paper presented at the European Formation Damage Conference, Scheveningen, the Netherlands. 2007, June.

53. Al-Anazi, H. A., Walker, J. G., Pope, G. A., Sharma, M. M., Hackney, D. F. A successful methanol treatment in a gas-condensate reservoir: Field application. Paper presented at the SPE Production and Operations Symposium, Oklahoma City, Oklahoma. 2003, March.

54. Franco, C. A., Romero, R. D. Z., Arango, J. F. Z., Mora, E., Botero, O. F., Candela, C. H., Mejia, A. F. C. Inhibited gas stimulation to mitigate condensate banking and maximize recovery in Cupiagua field. Paper presented at the SPE International Symposium and Exhibition on Formation Damage Control, Lafayette, Louisiana. 2012, February.

55. Ignatyev, A. E., Mukminov, I. R., Vikulova, E. A., Pepelyayev, R. V. Multistage hydraulic fracturing in horizontal wells as a method for the effective development of gas-condensate fields in the Arctic region. Paper presented at the SPE Arctic and Extreme Environments Conference \& Exhibition held in Moscow, Russia. 2011, October.

56. Miller N., Nasrabadi, H., Zhu, D. Application of horizontal wells to reduce condensate blockage in gas condensate reservoirs. Paper presented at the CPS/SPE International Oil and Gas Conference and Exhibition, Beijing, China. 2010, June.

57. Han Seah, Yong \& Gringarten, Alain \& Ann Giddins, Marie \& Burton, Kirsty. Optimising Recovery in Gas Condensate Reservoirs. 2014

Рукопись поступила в редакцию 15.07.2019, принята к публикации 02.09.2019

\section{O6 авторах}

Волохова Алина Викторовна - младший научный сотрудник - Объединенный институт ядерных исследований - 141980, Московская обл, г. Дубна, ул. Жолио-Кюри, 6 - volokhova@jinr.ru $+7(49621) 63959$ 
Земляная Елена Валериевна - доктор физ.-мат. наук - начальник сектора - Объединенный институт ядерных исследований - 141980, Московская обл, г. Дубна, ул. Жолио-Кюри, 6 - elena@jinr.ru $+7(49621) 64728$.

Качалов Владимир Викторович - кандидат технических наук - старший научный сотрудник Объединенного института высоких температур РАН - 125412, г. Москва, ул. Ижорская, д. 13, стр. 2 ongk@mail.ru -8-495-485-91-45.

Сокотущенко Вадим Николаевич - кандидат технических наук - ведущий инженер Объединенного института высоких температур РАН, 125412 , г. Москва, ул. Ижорская, д. 13, стр. 2; sokotushenko@mail.ru-8-962-951-53-52.

\section{About the authors}

Volokhova Alina Viktorovna - Junior researcher - Joint Institute for Nuclear Research - 141980, Moscow region, Dubna, Joliot-Curie street, 6 volokhova@jinr.ru - +7(49621)63959. ScopusID: 56505574900

Zemlyanaya Elena Valerievna - doctor of physics and mathematics - head of sector - Joint Institute for Nuclear Research - 141980, Moscow region, Dubna, Joliot-Curie street, 6 elena@jinr.ru -+7(49621)64728. ScopusID: 6701729810

Kachalov Vladimir Viktorovich - candidate of technical sciences, senior researcher of the United Institute for high temperatures, Russian Academy of Sciences - 125412, Moscow, Izhorskaya str., 13, p. 2 - ongk@mail.ru-8-495-485-91-45. ScopusID: 6701510830

Sokotuschenko Vadim Nikolaevich - candidate of technical Sciences - leading engineer of the United Institute for high temperatures, Russian Academy of Sciences - 125412, Moscow, Izhorskaya str. - sokotushenko@mail.ru - 8-962-951-53-52. ScopusID: 57192655832. 